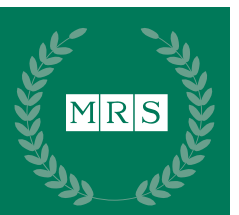

Materials Research Society seeks award nominations
For additional MRS award information including nomination requirements and deadlines, visit www.mrs.org/awards.

\section{Graduate Student Awards www.mrs.org/gsa}

MRS Graduate Student Awards are intended to honor and encourage graduate students whose academic achievements and current materials research display a high level of excellence and distinction. MRS seeks to recognize students of exceptional ability who show promise for significant future achievement in materials research.

Gold and Silver Awards are presented at the Award Session during the week of the MRS Meeting and announced in MRS Bulletin. The prizes consist of $\$ 400$ and a presentation plaque for the Gold Awards, and \$200 and a certificate for the Silver Awards.

\section{Arthur Nowick}

\section{Graduate Student Award}

The Arthur Nowick Graduate Student Award, which honors the late Dr. Arthur Nowick and his lifelong commitment to teaching and mentoring students in materials science, will be presented to a GSA finalist who shows particular promise as a future teacher and mentor. This award includes $\$ 500$ and a presentation plaque. This award will be presented at each MRS Spring and Fall Meeting.

\section{MRS Postdoctoral Awards \\ www.mrs.org/postdoctoral}

MRS acknowledges the Jiang Family

Foundation and MTI Corporation for their generous contributions to support this award.

The MRS Postdoctoral Awards recognize postdoctoral scholars who show exceptional promise that may include, for example, excellence in scientific research, leadership, advocacy, outreach, or teaching during their postdoc assignment.

Each award consists of a $\$ 2,000$ honorarium, citation certificate, meeting registration fee to attend the MRS Spring or Fall Meeting at which the award is presented, and a one-year MRS membership.

\section{Innovation in Materials Characterization Award www.mrs.org/imca}

The Innovation in Materials Characterization Award is endowed by Dr. Gwo-Ching Wang and Dr. Toh-Ming Lu. The Innovation in Materials Characterization Award honors an outstanding advance in materials characterization that notably increases the knowledge of the structure, composition, in situ behavior under outside stimulus, electronic, mechanical, or chemical behavior, or other characterization feature, of materials. It is not limited to the method of characterization or the class of materials observed. Impact of the advance on materials research is the primary consideration. Nominations for this award may be made for scientists and engineers in all areas of materials research.

The annual award consists of a $\$ 5,000$ cash prize, a presentation trophy, and a certificate. The award is presented annually at the MRS Spring Meeting. Meeting registration fee, transportation, and hotel expenses to attend the meeting at which the award is presented will be reimbursed.

\section{Mid-Career Researcher Award www.mrs.org/mra}

The Mid-Career Researcher Award is made possible through an endowment established by MilliporeSigma (Sigma-Aldrich Materials Science).

The Mid-Career Researcher Award recognizes exceptional achievements in materials research made by mid-career professionals. It is intended to honor an individual who is between the ages of 40 and 52 at the time of nomination. Exceptions may be made for an interruption in career progression due to family or military service. The award recipient must also demonstrate notable leadership in the materials area.

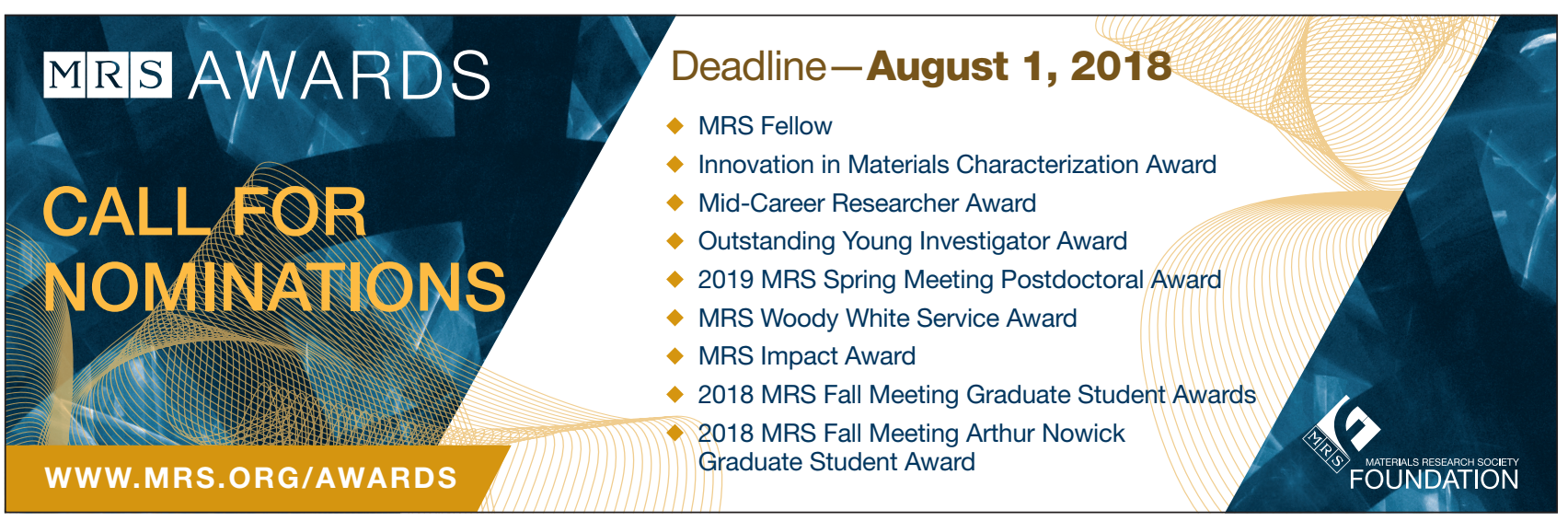


The annual award consists of a $\$ 5,000$ cash prize, a presentation trophy, and a certificate. Meeting registration fee, transportation, and hotel expenses to attend the MRS Spring Meeting at which the award is presented will be reimbursed.

\section{MRS Fellows}

\section{www.mrs.org/mrsfellows}

MRS seeks to recognize as MRS Fellows outstanding members whose sustained and distinguished contributions to the advancement of materials research are internationally recognized. It is intended that by representing excellence in science and engineering and dedication to the advancement of materials research, the MRS Fellows will exemplify the highest ideals of accomplishment and service embodied in the MRS Mission.

Fellowship selection is managed by the MRS Fellow Subcommittee of the MRS Awards Committee.This subcommittee is responsible for evaluating nominations annually and recommending successful nominees to the MRS Board for final approval. The appointments of newly selected Fellows will be announced during January or February of each year, and new Fellows will be honored during the MRS Spring Meeting.

\section{Outstanding Young Investigator Awards www.mrs.org/oyi}

The OYI Awards recognize outstanding interdisciplinary scientific work in materials research by scientists or engineers under the age of 36 (as of January 1, 2018). The award recipients must show exceptional promise as developing leaders in the materials area.

Each award consists of a $\$ 5,000$ prize, a presentation trophy, and a citation certificate. Reasonable travel expenses to attend the MRS Spring Meeting at which the award is presented and the meeting registration fee will be reimbursed.

\section{MRS Impact Award}

www.mrs.org/mrs-impact-award

The MRS Impact Award honors outstanding individuals who have displayed excellence in areas of science communication, education, advancing diversity, mentoring, or community engagement, which reflect the Society's pursuit to advance materials science and technology to improve the quality of life.

Each prize consists of a $\$ 5,000$ cash prize, an award trophy, a citation certificate, meeting registration fee to attend the MRS Spring Meeting at which the award is presented, and a one-year MRS membership. Additionally, reasonable travel and hotel expenses to attend the MRS Meeting will be reimbursed. (When a team is recognized, the cash prize will be split equally, but each individual shall receive a trophy and certificate.)

\section{MRS Woody White Service Award} www.mrs.org/woody-white The MRS Woody White Service Award honors outstanding individuals who have embodied MRS' Mission, Vision and Values for an egalitarian interdisciplinary community advancing materials science and technology to improve the quality of life. It may be given in recognition of longterm, impactful service to the Society, as well as for special projects/programs that have significantly impacted the Society.

The award consists of a certificate and a lifetime MRS membership, as well as a meeting registration waiver, and a travel stipend to attend the MRS Spring Meeting at which the award is presented.

\section{MRS Bulletin Postdoctoral Publication Prize \\ www.mrs.org/bulletin-prize}

MRS Bulletin acknowledges the Jiang Family Foundation and MTI Corporation for their generous contributions to support this prize.

The MRS Bulletin Postdoctoral Publication Prize recognizes postdoctoral researchers for their intellectual merit and for their ability to promote effective writing and communications through an interest in scientific publications. Candidates should show promise for future scientific contributions and scholarship in the broad materials field as well as demonstrated interest in scientific writing and communications.

The recipient receives $\$ 2,000$, a profile published in MRS Bulletin, complimentary one-year membership in MRS, invitation to publish in MRS Bulletin, and recognition at the MRS Fall Meeting. Application deadline is 5:00 pm (ET) July 31, 2018.

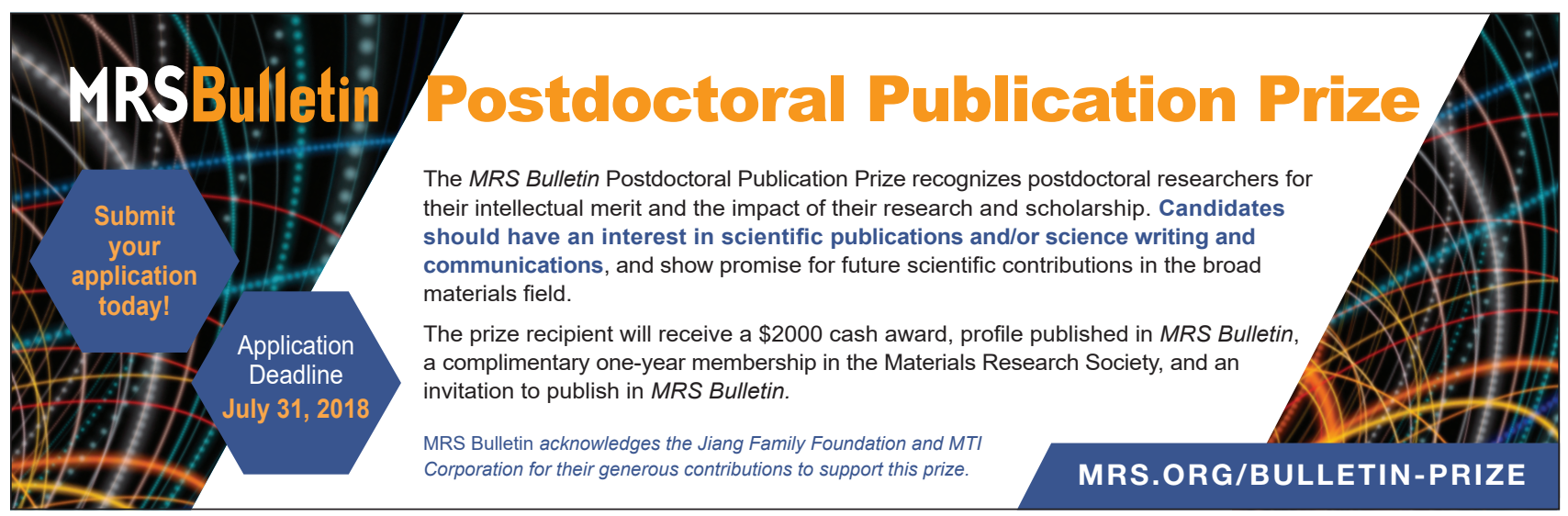

